\section{Quantitative Evaluation of Electric Light Recipes for Red Leaf Lettuce Cultivation in Plant Factories}

\author{
Hsing-Ying Chung ${ }^{1}$, Ming-Yih Chang ${ }^{2}$, Chia-Chyi $\mathrm{Wu}^{3}$, \\ and Wei Fang ${ }^{1,4}$
}

AdDitional INDEX wORDs. anthocyanin, energy yield, LED, light-emitting diode, photon yield, quantitative indicator

Summary. Red leaf lettuce (Lactuca sativa) has high nutritional value and is frequently used in salads. In a plant factory with full electric lighting, if the spectrum is incorrect, then red leaf lettuce will have incomplete coloration. This study aimed to establish a light recipe for the mass production of red leaf lettuce using electric light sources in a plant factory by using indicators for quantitative assessment, including energy yield (EY) [grams of fresh weight (FW) harvested per kilowatt hour of electricity input for lighting], photon yield (PY) (grams of FW harvested per mole of photons delivered), anthocyanin yield per kilowatt hour $\left(E Y_{A}\right)$, and anthocyanin yield per photon $\left(P Y_{A}\right)$. First, the effects of four types of light quality on FW and anthocyanin content were examined. Then, two types of light quality, light-emitting diode with a red-to-blue photon ratio of $80: 20\left(\mathbf{R}_{80}: \mathbf{B}_{20}\right)$ and $R_{20}: B_{80}$, were selected for an experiment involving five treatments. An optimum light recipe (SR5SBI) including $R_{80}: B_{20}$ treatment during the early stage of cultivation (weeks 1 through 5 after sowing) followed by $R_{20}: B_{80}$ treatment during the final stage (week 6) was proposed. The SR5SBI treatment led to FW, $\mathrm{EY}_{\mathrm{A}}$, and $\mathrm{PY}_{\mathrm{A}}$ of $87.8 \mathrm{~g} /$ plant, $1.63 \mathrm{mg} / \mathrm{kWh}$, and $0.57 \mathrm{mg} \cdot \mathrm{mol}^{-1}$, respectively. This treatment resulted in the highest $\mathrm{EY}_{\mathrm{A}}$ and $\mathrm{PY}_{\mathrm{A}}$, with $159 \%$ and $256 \%$ more anthocyanin productivity, respectively, compared with cool white treatment (with $\mathrm{FW}, \mathrm{EY}_{\mathrm{A}}$, and $\mathrm{PY}_{\mathrm{A}}$ of $65.8 \mathrm{~g} / \mathrm{plant}, 0.63 \mathrm{mg} / \mathrm{kWh}$, and $0.16 \mathrm{mg} \cdot \mathrm{mol}^{-1}$, respectively). The proposed SR5SBI light recipe enabled cultivation of red leaf lettuce with a balanced yield and anthocyanin production.

$\mathrm{T}$ he issue of food safety has gained attention in recent years. Currently, climate change is a major concern, and it is increasingly difficult to cultivate healthy and safe agricultural products in the field (Sazvar et al., 2018). Plant factories can provide a cultivation environment that is free from disturbances by the external environment and have steady annual production; therefore, they have great potential for safe crop production (Kozai, 2013). In Taiwan, red leaf lettuce contains anthocyanin and appears red; therefore, it is used for color enhancement in salads (Gazula et al., 2007). Lee et al. (2009) found that red leaf lettuce can help reduce

${ }^{1}$ Department of Bio-Industrial Mechatronics Engineering, National Taiwan University, No. 1, Sec. 4, Roosevelt Road, Taipei, Taiwan, 106, R.O.C

${ }^{2}$ Department of Biomechatronic Engineering, National Ilan University, No. 1, Sec. 1, Shen-Lung Road, I-Lan, Taiwan, 260, R.O.C.

${ }^{3}$ Department of Horticulture, National Ilan University, No. 1, Sec. 1, Shen-Lung Road, I-Lan, Taiwan, 260, R.O.C.

${ }^{4}$ Corresponding author. E-mail: weifang@ntu.edu.tw.

https://doi.org/10.21273/HORTTECH04024-18 the risk of cardiovascular disease in mice. Current plant factories with full electric lighting primarily use light from white light-emitting diodes (LEDs) as the light source for cultivation; however, these light sources do not emit ultraviolet light, and the spectra are considerably different from sunlight. Previous studies have mentioned that although ultraviolet light causes substantial accumulation of anthocyanin and secondary metabolites in red leaf lettuce, excessive ultraviolet light slows the growth of lettuce (Tsormpatsidis et al., 2010).
In a plant factory with electric light, both the fixed cost of acquiring electric light sources and the subsequent operating cost expended each day are remarkably high. The cost of electric energy may exceed $25 \%$ of the total production cost (Kozai, 2013); therefore, the selection of electric light sources is a crucial topic of discussion. Scholars have conducted numerous studies of photosynthetic photon flux density (PPFD), light quality, and photoperiods. A PPFD of $300 \mu \mathrm{mol} \cdot \mathrm{m}^{-2} \cdot \mathrm{s}^{-1}$ can significantly increase red perilla (Perilla frutescens) growth and anthocyanin content compared with lower PPFD treatments (Lu et al., 2017). Furthermore, a mixture of red and blue electric light sources can increase anthocyanin content more than green light sources can (Nishimura et al., 2009). The total phenolic concentration, total flavonoid concentration, and anthocyanin content of lettuces grown under high ratios of blue light $\left(\mathrm{B}_{59}, \mathrm{~B}_{47}\right.$, and $B_{35}$ ) were significantly higher compared those grown with $\mathrm{B}_{0}$ treatment (Son and Oh, 2013). Supplemental blue light $\left(\mathrm{R}_{14}: \mathrm{G}_{31}: \mathrm{B}_{55}\right)$ for baby leaf lettuce can enhance anthocyanin accumulation and increase carotenoid concentration ( $\mathrm{Li}$ and Kubota, 2009). Compared with a 12 -h photoperiod, a $16-\mathrm{h}$ photoperiod can significantly increase the concentration of rosmarinic acid in spearmint [Mentha spicata (Fletcher et al., 2010)]. However, this series of studies lacked a quantitative assessment of the energy consumption of electric light sources used for crop production; therefore, it lacked an important metric for the selection of lamps.

The concepts of energy yield (EY) and photon yield (PY) are aimed at assessing the effectiveness of electric light sources for cultivating crops in plant factories. The unit of $\mathrm{EY}$ is grams per kilowatt hour and represents the grams of shoot fresh weight

\begin{tabular}{llll}
\hline $\begin{array}{l}\text { Units } \\
\text { To convert U.S. to SI, } \\
\text { multiply by }\end{array}$ & U.S. unit & SI unit & $\begin{array}{l}\text { To convert SI to U.S., } \\
\text { multiply by }\end{array}$ \\
\hline 10 & $\%$ & $\mathrm{mg} \cdot \mathrm{g}^{-1}$ & 0.1 \\
29.5735 & $\mathrm{fl} \mathrm{oz}$ & $\mathrm{mL}$ & 0.0338 \\
0.0929 & $\mathrm{ft}^{2}$ & $\mathrm{~m}^{2}$ & 10.7639 \\
2.54 & inch $(\mathrm{es})$ & $\mathrm{cm}$ & 0.3937 \\
1 & $\mathrm{mmho} / \mathrm{cm}$ & $\mathrm{mS} \cdot \mathrm{cm}^{-1}$ & 1 \\
28.3495 & $\mathrm{oz}$ & $\mathrm{g}$ & 0.0353 \\
28,350 & $\mathrm{oz}$ & $\mathrm{mg}$ & $3.5274 \times 10^{-5}$ \\
10.7639 & $\mathrm{~W} / \mathrm{ft}^{2}$ & $\mathrm{~W} \cdot \mathrm{m}^{-2}$ & 0.0929 \\
$\left({ }^{\circ} \mathrm{F}-32\right) \div 1.8$ & ${ }^{\circ} \mathrm{F}$ & ${ }^{\circ} \mathrm{C}$ & $\left({ }^{\circ} \mathrm{C} \times 1.8\right)+32$ \\
$\left({ }^{\circ} \mathrm{F} \div 1.8\right)+255.37$ & ${ }^{\circ} \mathrm{F}$ & $\mathrm{K}$ & $(\mathrm{K}-255.37) \times 1.8$
\end{tabular}


(FW) that can be produced by a plant per kilowatt hour of electricity consumed during the entire crop cycle. The higher the EY value, the more efficiently a plant converts electric energy into FW (Fang, 2013). EY can also be used to improve secondary metabolite production in plants. Using anthocyanin as an example, $\mathrm{EY}_{\mathrm{A}}$ indicates the milligrams of anthocyanin that can be produced by a plant per kilowatt hour of electricity consumed during the crop cycle. The unit of PY is grams per mole and represents the grams of FW that can be produced by a plant per mole of photosynthetically active radiation $(P A R)$. Higher PY values indicate greater efficiency with which a plant uses each mole of photons to produce FW. The PY is affected by PPFD and light quality. Similarly, $\mathrm{PY}_{\mathrm{A}}$ represents the amount (milligrams) of anthocyanin that can be produced by a plant per mole of photosynthetically active photons. Obviously, crop yields are influenced not only by light delivery but also by nutrients received, indoor temperature, humidity, ventilation, management, and when and how to apply light.

This study paired different light qualities with different illumination strategies to examine the growth and anthocyanin production of red leaf lettuce, and it used EY and PY as indicators for assessing the effects of energy consumption of an electric light source and its spectrum on crop production in a plant factory. This study evaluated light recipes, including when light was provided, how intense the light was (PPFD), how long the light was on (photoperiod), and what type of spectrum was provided during specific stages of lettuce cultivation.

\section{Materials and methods}

EXPT. 1: EFFECTS OF DIFFERENT AMOUNTS OF RED AND BLUE LIGHT RATIOS ON THE GROWTH AND PHYSIOLOGY OF RED LEAF LETTUCE. The red leaf lettuce cultivar Red Oak was used in this study (Suntech Seed Co., Tainan, Taiwan). Seeds were soaked in tap water for $5 \mathrm{~h}$; after which, floating seeds were removed and the remaining seeds were sown in moist sponge media (Yung-Kuang Chemical Products Co., Taichung, Taiwan) and placed in a growth chamber with a temperature of $20{ }^{\circ} \mathrm{C}$. Cool white (CW) LED lamps (Genesis Photonics, Tainan, Taiwan) were used for 24-h illumination. The PPFD of each treatment group was measured using a quantum sensor (LI-250A light meter, LI-190R sensor; LI-COR, Lincoln, NE) and maintained at 100 $\pm 5 \mu \mathrm{mol} \cdot \mathrm{m}^{-2} \cdot \mathrm{s}^{-1}$ at $25 \mathrm{~cm}$ below the light source during the sowing stage. Settings for additional environmental parameters during the cultivation period are listed in Table 1.

Expt. 1 used four different light qualities, including three R-B light combinations and CW LED lamps. The R-B treatments comprised three different photon ratios: $\mathrm{R}_{80}: \mathrm{B}_{20}, \mathrm{R}_{50}$ : $\mathrm{B}_{50}$, and $\mathrm{R}_{20}: \mathrm{B}_{80}$ (Test model; Everlight Electronics Co., New Taipei City, Taiwan). The fourth treatment, which was used as the control, used CW LEDs with a color temperature of $5500 \mathrm{~K}$. The PPFD used during each treatment was measured using a quantum sensor and maintained at $150 \pm 5 \mu \mathrm{mol} \cdot \mathrm{m}^{-2} \cdot \mathrm{s}^{-1}$. A spectroradiometer (USB4000; Ocean Optics, Largo, FL) was used to measure the light spectrum of each treatment (Fig. 1). Energy consumption of the light source was measured using a current clamp-on meter (368FC; FLUKE, Everett, WA), and the power consumed per unit of growing area was calculated (Table 2). Table 2 shows the absolute values of the PPFD in the blue, green, and red wavebands. Plants were harvested $42 \mathrm{~d}$ after sowing.

EXPT. 2: EFFECTS OF DIFFERENT COMBINATIONS OF RED AND BLUE LIGHT RATIOS DURING DIFFERENT GROWTH STAGES ON THE ANTHOCYANIN CONTENTS OF RED LEAF LETTUCE. The same red leaf lettuce cultivar that was used for Expt. I was used for Expt. 2, and two types of R-B LEDs were used: one system with stronger red (SR) and another with stronger blue ( $\mathrm{SB}$ ). The ratios of R-B photons were $\mathrm{R}_{80}: \mathrm{B}_{20}$ and $\mathrm{R}_{20}: \mathrm{B}_{80}$. The spectra and intensity values used are shown in Fig. 1 and in the second and fourth columns of Table 2. Both light sources produced a PPFD of $150 \pm 5 \mu \mathrm{mol} \cdot \mathrm{m}^{-2} \cdot \mathrm{s}^{-1}$. During cultivation, three out of five LED treatments were switched to different spectra at 3,2 , and 1 weeks before harvest (Table 3). The first column of Table 3 shows the treatments of each arrangement

Table 1. Environmental parameters, including air temperature, light parameters, nutrition solution parameters, and carbon dioxide concentration, used for red lettuce cultivation.

\begin{tabular}{|c|c|c|c|c|}
\hline Environmental parameters & $\begin{array}{c}\text { Units } \\
(\text { mean } \pm S D)^{z}\end{array}$ & Sowing stage 0-6 DAS ${ }^{y}$ & Seedling stage 7-13 DAS & $\begin{array}{c}\text { Growing stage } \\
\text { 14-42 DAS }\end{array}$ \\
\hline Day/night temperature & ${ }^{\circ} \mathrm{C}$ & $20 \pm 2$ & \multicolumn{2}{|c|}{$25 / 18 \pm 2$} \\
\hline Light quality $^{\mathrm{w}}$ & - & CW & \multicolumn{2}{|c|}{$\mathrm{R}_{80}: \mathrm{B}_{20} / \mathrm{R}_{50}: \mathrm{B}_{50} / \mathrm{R}_{20}: \mathrm{B}_{80} / \mathrm{CW}$} \\
\hline Photoperiod & $\mathrm{h}$ & 24 & \multicolumn{2}{|c|}{16} \\
\hline Plants density & plants $/ \mathrm{m}^{2}$ & 667.6 & 140.3 & 30.6 \\
\hline $\mathrm{pH}$ & - & \multicolumn{3}{|c|}{$6.0 \pm 0.1$} \\
\hline Hydroponic type & - & Still water culture & \multicolumn{2}{|c|}{ Deep flow technique } \\
\hline $\begin{array}{l}\text { Carbon dioxide } \\
\text { concentration }\end{array}$ & $\mu \mathrm{mol} \cdot \mathrm{mol}^{-1}$ & \multicolumn{3}{|c|}{$1200 \pm 100$} \\
\hline
\end{tabular}


of LED lights. They were SR6 [SR $\left(\mathrm{R}_{80}\right.$ : $\mathrm{B}_{20}$ ) for 6 weeks], SR5SBl [SR for 5 weeks followed by $\mathrm{SB}\left(\mathrm{R}_{20}: \mathrm{B}_{80}\right)$ for 1 week], SR4SB2 (SR for 4 weeks followed by SB for 2 weeks), SR3SB3 (SR for 3 weeks followed by SB for 3 weeks), and SB6 (SB for 6 weeks). During Expt. 2, after 6 weeks of cultivation, FW, anthocyanin content, and chromaticity coordinates of the leaves were measured and analyzed.

\section{Measurements}

Chromaticity coordinates of THE LEAVES. Fully expanded upper leaves were selected after 6 weeks of cultivation. Each leaf was measured at three different locations. Five plants were randomly selected for sampling and examined with a colorimeter (6807 color-guide 45/0; BYK-Gardner, Wesel, Germany). The $L^{*}$ value indicated the degree of lightness (black: $L^{*}=$ 0; white: $\left.L^{*}=100\right)$, the $a^{*}$ value indicated the degrees of green $\left(a^{*}=-60\right)$ and red $\left(a^{*}=+60\right)$, and the $b^{*}$ value indicated the degrees of blue $\left(b^{*}=-60\right)$ and yellow $\left(b^{*}=+60\right)$. The hue angle $\left(b^{\circ}\right)$ was calculated using Eq. [1]. The $b^{\circ}$ close to $0^{\circ}$ indicated a color close to red, and $h^{\circ}$ close to $180^{\circ}$ indicated a color close to green (Owen and Lopez, 2015).

$$
b^{\circ}=\tan ^{-1}\left(\frac{b^{*}}{a^{*}}\right)
$$

Analysis of anthocyanin CONTENT AND SHOOT FW OF LETTUCE.

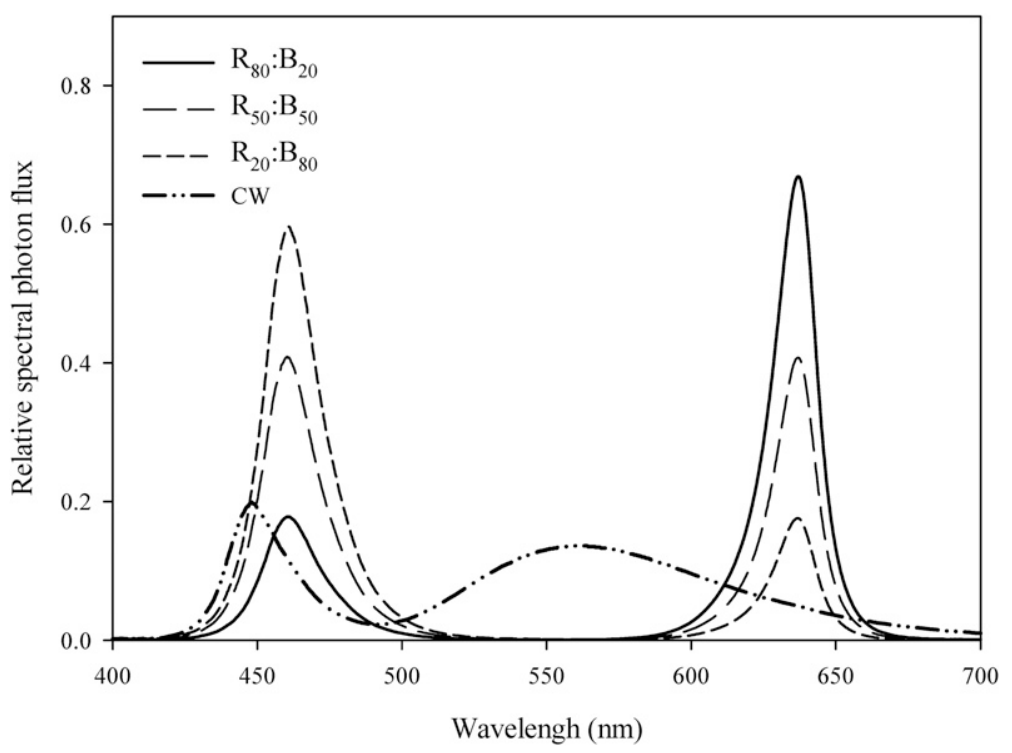

Fig. 1. Spectral distributions of light from light-emitting diodes (LEDs) measured with a spectroradiometer. Different LED light quality treatments were used. The red-blue photon ratios were $R_{80}: B_{20}, R_{50}: B_{50}$, and $R_{20}: B_{80}$, respectively. The cool white $(C W)$ red-green-blue photon ratio was $R_{20}: G_{50}: B_{30}$. Photon flux per unit wavelength is expressed relative to the maximum.
After the lettuce was harvested, the aboveground portion was removed and weighed on an electronic balance (STX2202; OHAUS, Parsippany, NJ) to obtain the shoot FW (in grams). Next, fully expanded upper leaves were selected. Five plants were randomly selected for sampling. Using the method described by Hung et al. (2008), $0.5 \mathrm{~g}$ of fresh lettuce leaves were randomly collected from each treatment group. After the samples had been ground with liquid nitrogen in a mortar, $2 \mathrm{~mL}$ of tripotassium phosphate buffer solution was added and evenly mixed. The samples were placed in a $1.5-\mathrm{mL}$ centrifuge tube and centrifuged at $4{ }^{\circ} \mathrm{C}$ and $9500 g_{n}$ for $30 \mathrm{~min}(\mathrm{Z} 216 \mathrm{MK}$; HERMLE, Wehingen, Germany). A spectrophotometer (DR2800; Hach, Loveland, $\mathrm{CO}$ ) was used to determine the absorbance at a wavelength of $600 \mathrm{~nm}$. A standard cyanidin-3-Oglucoside solution in methanol with $1 \% \mathrm{HCl}$ (Sigma-Aldrich, St. Louis, MO) was used to establish a calibration curve to obtain the anthocyanin content [AC (milligrams per gram)] of FW.

Eq. [2] shows that the AC and the shoot FW of lettuce (grams per plant) were multiplied to obtain the total anthocyanin content [TAC (milligrams per plant)]:

$$
\mathrm{TAC}=\mathrm{AC} \times \mathrm{FW}
$$

EY AND PY. Calculations for EY and PY were based on the formula published by Fang (2013). EY and $\mathrm{EY}_{\mathrm{A}}$ incorporated represent the $\mathrm{FW}$ of lettuce and the TAC that can be produced, respectively, by an electric light source per kilowatt hour of electricity consumed between sowing

Table 2. Characteristics of four light-emitting diode (LED) treatments installed $25 \mathrm{~cm}(9.8$ inches) directly above the lettuce seedling. The cool white LED (CW) treatment was the control. The PPFD in the blue, green, and red wavebands for the

\begin{tabular}{|c|c|c|c|c|}
\hline \multirow[b]{2}{*}{ Expt. 1 parameters } & \multicolumn{4}{|c|}{ Treatment } \\
\hline & $\mathrm{R}_{80}: \mathrm{B}_{20}$ & $\mathrm{R}_{50}: \mathrm{B}_{50}$ & $\mathrm{R}_{20}: \mathrm{B}_{80}$ & CW \\
\hline & \multicolumn{4}{|c|}{ Light intensity $\left[\text { mean } \pm \mathrm{SD}\left(\mu \mathrm{mol} \cdot \mathrm{m}^{-2} \cdot \mathrm{s}^{-1}\right)\right]^{\mathrm{z}}$} \\
\hline Blue $(400-499 \mathrm{~nm})$ & $30 \pm 5$ & $75 \pm 5$ & $120 \pm 5$ & $45 \pm 5$ \\
\hline Green (500-599 nm) & 0 & 0 & 0 & $75 \pm 5$ \\
\hline $\operatorname{Red}(600-699 \mathrm{~nm})$ & $120 \pm 5$ & $75 \pm 5$ & $30 \pm 5$ & $30 \pm 5$ \\
\hline
\end{tabular}
different light treatments is shown.

${ }^{z}$ Photosynthetic photon flux density $[P P F D(400-700 \mathrm{~nm})]$ was measured using a quantum sensor at $25 \mathrm{~cm}(9.8$ inches $)$ below the light source.

${ }^{\mathrm{y}} 1 \mathrm{~W} \cdot \mathrm{m}^{-2}=0.0929 \mathrm{~W} / \mathrm{ft}^{2}$. 
Table 3. Using two types of light-emitting diodes (red-blue ratios $R_{80}: B_{20}$ and $R_{20}: B_{80}$ ) for different durations, a total of five different treatments were used for red lettuce cultivation (Expt. 2). ${ }^{\mathrm{z}}$

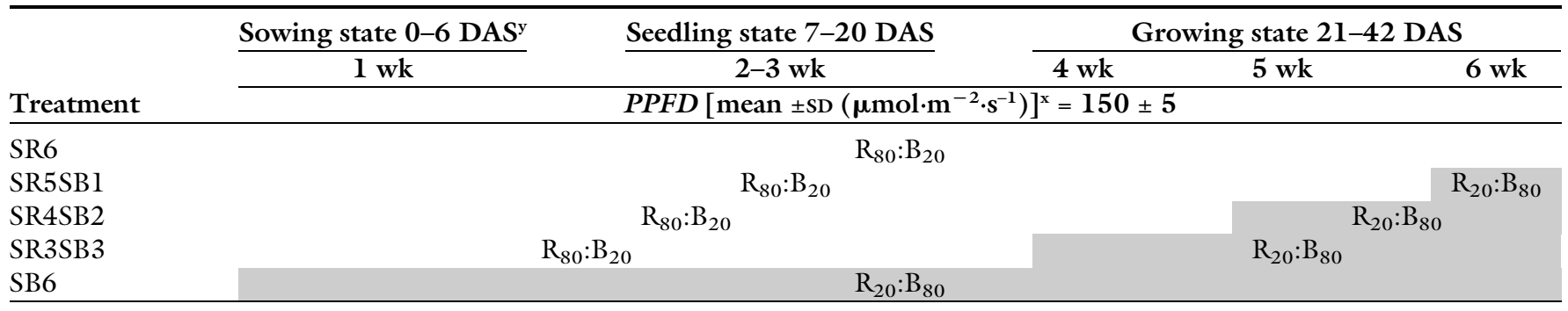

${ }^{\mathrm{z}}$ For environmental parameters other than light treatment, please refer to Table 1.

${ }^{y}$ Days after sowing.

${ }^{\mathrm{x}}$ Photosynthetic photon flux density $[P P F D(400-700 \mathrm{~nm})]$ was measured using a quantum sensor at $25 \mathrm{~cm}(9.8$ inches $)$ below the light source.

and harvesting. The equations are as follows:

$$
\begin{aligned}
\mathrm{TPI}_{\mathrm{i}} & =\left(\mathrm{P}_{\mathrm{i}} \times \mathrm{N}_{\mathrm{i}} \times \mathrm{L}_{\mathrm{i}} \div 1000\right) \times \mathrm{d}_{\mathrm{i}} / \mathrm{Pd}_{\mathrm{i}} \\
\mathrm{OTPI} & =\sum_{\mathrm{i}=1}^{\mathrm{n}} \mathrm{TPI}_{\mathrm{i}} \\
\mathrm{EY} & =\mathrm{FW} / \mathrm{OTPI} \\
\mathrm{EY}_{\mathrm{A}} & =\mathrm{TAC} / \mathrm{OTPI}
\end{aligned}
$$

Total power integral per plant at stage $\mathrm{i}\left(\mathrm{TPI}_{\mathrm{i}}\right)$ is described as follows: during cultivation, stage $\mathrm{i}$ represents the electric energy consumed by the lights (in kilowatt hours per plant). The i represents the different stages of cultivation. Power at stage $\mathrm{i}\left(\mathrm{P}_{\mathrm{i}}\right)$ is described as follows: during cultivation, stage $\mathrm{i}$ represents the electric power consumed per electric light source (in watts). The number of lights at cultivation stage $\mathrm{i}\left(\mathrm{N}_{\mathrm{i}}\right)$ represents the average number of electric light sources (tubes or panels) used per square meter of growing area. Daily lighting hours at cultivation stage $\mathrm{i}\left(\mathrm{L}_{\mathrm{i}}\right)$ represents the daily photoperiod (in hours per day). Days at cultivation stage $i\left(d_{i}\right)$ represents the number of days for cultivation stage $i$. Planting density at cultivation stage $\mathrm{i}\left(\mathrm{Pd}_{\mathrm{i}}\right)$ represents the planting density (in plants per square meter). Overall total power integral (OTPI) represents the total light energy consumption during the entire cultivation period (in kilowatt hours per plant). EY is the FW per lettuce plant that can be produced by using electric lights (in grams per kilowatt hour). $\mathrm{EY}_{\mathrm{A}}$ is the TAC (milligrams) per lettuce plant that can be produced by using lights (in milligrams per kilowatt hour).

$\mathrm{PY}$ and $\mathrm{PY}_{\mathrm{A}}$ represent the $\mathrm{FW}$ and TAC, respectively, that can be produced per mole of photons delivered from electric light sources. The equations are as follows:

$$
\begin{aligned}
\mathrm{TLI}_{\mathrm{i}}= & \left(P P F D_{\mathrm{i}} \times \mathrm{L}_{\mathrm{i}} \times 3.6 / 1000\right) \\
& \times \mathrm{d}_{\mathrm{i}} / \mathrm{Pd}_{\mathrm{i}} \\
\mathrm{OTLI}= & \sum_{\mathrm{i}=1}^{\mathrm{n}} \mathrm{TLI}_{\mathrm{i}} \\
\mathrm{PY}= & \mathrm{FW} / \mathrm{OTLI} \\
\mathrm{PY}_{\mathrm{A}}= & \text { TAC } / \text { OTLI }
\end{aligned}
$$

Total light integral per plant at cultivation stage $\mathrm{i}\left(\mathrm{TLI}_{\mathrm{i}}\right)$ represents the total cumulative PPFD per plant (in moles per plant). Photosynthetic photon flux density at cultivation stage $\mathrm{i}\left(P P F D_{\mathrm{i}}\right)$ represents the average $P A R$ (in micromoles per square meter per second). Overall total light integral per plant (OTLI) represents the total accumulated PPFD per plant during the entire cultivation period (in moles per plant). PY and $\mathrm{PY}_{\mathrm{A}}$ are measured in grams and milligrams per mole, respectively.

The quantities EY and PY can be used to calculate the overall photon energy (OPE) ratio (moles per kilowatt hour), as shown in Eq. [11].

$$
\mathrm{OPE}=\mathrm{EY} / \mathrm{PY}
$$

For the PAR efficacy of luminaires, the unit micromoles per joule $\left(1 \mathrm{\mu mol} \cdot \mathrm{J}^{-1}=3.6 \mathrm{~mol} / \mathrm{kWh}\right)$ is used. It represents the PPFD (micromoles per second per square meter) of photons generated by the light per watt (joules per second) of electric power. Although the PPFD per watt and OPE are expressed as the same units, they represent different concepts.

Statistical analysis. This experiment used a completely randomized design and was replicated twice.
There were 20 samples for FW and five samples for anthocyanin content, chromaticity coordinates, EY and PY measurements, and calculations. Statistical software (SAS version 9.1; SAS Institute, Cary, NC) was used for analyses. Duncan's multiple range test was used for treatment comparisons $(P \leq 0.05)$.

\section{Results}

EXPT. 1: EFFECTS OF DIFFERENT AMOUNTS OF RED AND BLUE LIGHT RATIOS ON THE GROWTH AND PHYSIOLOGY OF RED LEAF LETTUCE. Results of the experiment showed that the $\mathrm{R}_{80}: \mathrm{B}_{20}$ treatment group produced the most FW (Table 4). Although the $\mathrm{R}_{20}: \mathrm{B}_{80}$ treatment group did achieve color changes in the leaves, the biomass production was clearly reduced (Fig. 2). Table 4 shows the FW, AC, and TAC of the three light quality treatments and the control treatment. The $\mathrm{R}_{80}: \mathrm{B}_{20}$ treatment significantly increased the shoot FW of lettuce, which caused the TAC to be the highest. As the proportion of blue light increased, the AC increased, but the shoot FW of lettuce significantly decreased (Table 4 ). The $\mathrm{R}_{20}: \mathrm{B}_{80}$ treatment significantly increased the AC of red leaf lettuce.

In terms of TAC, $\mathrm{R}_{80}: \mathrm{B}_{20}$ treatment increased production by $117 \%$ compared with CW treatment. Regarding the chromaticity coordinates of the leaves, $\mathrm{R}_{80}: \mathrm{B}_{20}$ and $\mathrm{CW}$ treatments did not show significant differences in the four chromaticity coordinates listed in Table 4 . The $\mathrm{R}_{80}$ $: \mathrm{B}_{20}$ and $\mathrm{CW}$ treatments significantly increased the values of $L^{*}$ (lightness), $b^{*}$ (blue and yellow), and $b^{\circ}$ (hue angle) compared with the $\mathrm{R}_{50}: \mathrm{B}_{50}$ and $\mathrm{R}_{20}: \mathrm{B}_{80}$ treatments. The $\mathrm{R}_{20}$ : $\mathrm{B}_{80}$ treatment significantly increased the $a^{*}$ value (green and red) and 


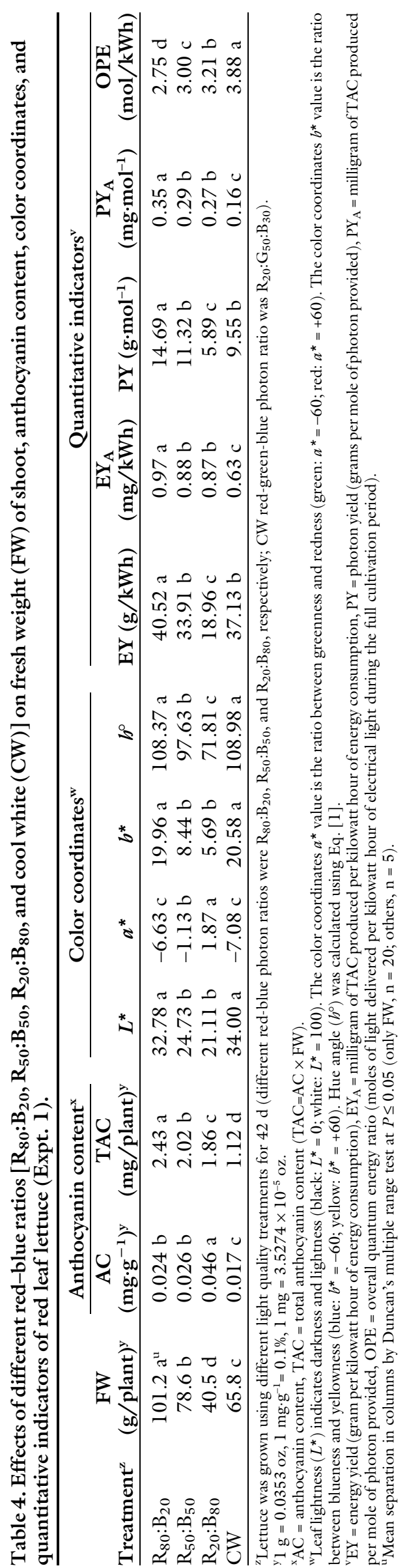

significantly decreased the $b^{*}$ and $b^{\circ}$ values compared with the $\mathrm{CW}$ treatment, which confirmed that the leaves had turned distinctly red and dark (Table 4; Fig. 2).

As shown in Table 4, the EY, $\mathrm{EY}_{\mathrm{A}}, \mathrm{PY}$, and $\mathrm{PY}_{\mathrm{A}}$ after $\mathrm{R}_{80}: \mathrm{B}_{20}$ treatment were the highest, whereas the $\mathrm{EY}_{\mathrm{A}}$ and $\mathrm{PY}_{\mathrm{A}}$ after $\mathrm{CW}$ treatment were the lowest. The EY and PY of the $\mathrm{R}_{20}: \mathrm{B}_{80}$ treatment were the lowest, indicating that the electricity consumption and spectrum of the $R_{20}$ : $\mathrm{B}_{80}$ light source benefited the accumulation of $\mathrm{FW}$ the least. Of the four light quality treatments, $\mathrm{R}_{80}: \mathrm{B}_{20}$ was the most favorable and $\mathrm{CW}$ had the highest OPE value of all light treatments. However, regarding the EY, $\mathrm{PY}, \mathrm{EY}_{\mathrm{A}}$, and $\mathrm{PY}_{\mathrm{A}}$ shown in Table 4, $\mathrm{CW}$ treatment achieved results similar to those of $\mathrm{R}_{50}: \mathrm{B}_{50}$ in terms of $\mathrm{EY}$ and PY, whereas its anthocyanin accumulation $\left(\mathrm{EY}_{\mathrm{A}}\right.$ and $\left.\mathrm{PY}_{\mathrm{A}}\right)$ was the least favorable.

Expt. 2: EFFECTS OF DIFFERENT COMBINATIONS OF RED AND BLUE RATIOS DURING DIFFERENT GROWTH STAGES ON ANTHOCYANIN CONTENTS OF RED LEAF LETTUCE. The results showed that lettuce growth during the SB6 treatment was suppressed and that growth of the SR6 treatment group was more favorable. However, color changes were poor, and the growth and color changes of the SR5SBl treatment group were more balanced (Fig. 3).

As shown in Table 5, although the SR6 treatment significantly increased FW, it also significantly decreased AC. The SR5SBl treatment significantly increased the TAC of lettuce. Although the SB6 treatment significantly increased AC, the TAC was also the lowest due to its low FW. A comparison between the SR5SBI and SB6 treatment groups (SR5SBl/ SB6) showed that the ratio values for FW, AC, and TAC were 2.03, 1.00 , and 2.05 , respectively.

Table 5 shows that when the SR6 treatment of $\mathrm{R}_{80}: \mathrm{B}_{20}$ was used for the entire process, the $L^{*}, b^{*}$, and $b^{\circ}$ values were the highest, whereas the $a^{*}$ value was the lowest. Moreover, if $\mathrm{R}_{20}: \mathrm{B}_{80}$ was used as the illumination treatment, regardless of whether it was for 6 weeks (SB6) or only l week (SR5SBl), then the $L^{*}, b^{*}$, and $b^{\circ}$ values were significantly decreased and the $a^{*}$ value was significantly increased. The SR5SBI treatment 


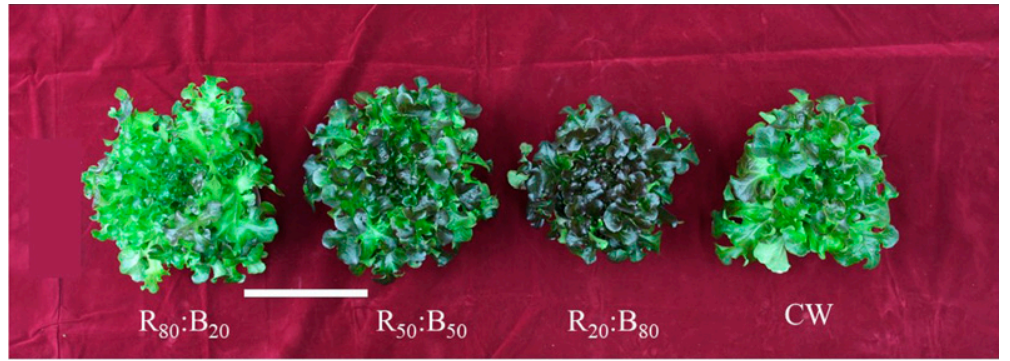

Fig. 2. Effects of different light quality treatments on the growth and development of red leaf lettuce $42 \mathrm{~d}$ after sowing [bar $=15.0 \mathrm{~cm}(5.91$ inches $)]$. The different light-emitting diode (LED) light quality treatments were as follows: red-blue photon ratios of $R_{80}: B_{20}, R_{50}: B_{50}$, and $R_{20}: B_{80}$, respectively, and the cool white (CW) red-green-blue photon ratio was $R_{20}: G_{50}: B_{30}$.

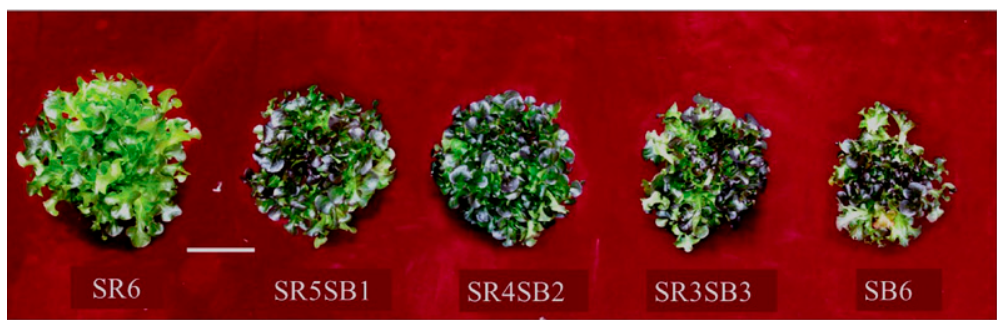

Fig. 3. Effects of different red-blue light ratios on the growth and development of red leaf lettuce $42 \mathrm{~d}$ after sowing [ $\mathrm{bar}=15.0 \mathrm{~cm}(5.91$ inches $)]$. SR6 represents light quality treatment $R_{80}: B_{20}$ for the full 6 weeks. SR5SBI represents $R_{80}: B_{20}$ during the first 5 weeks and $R_{20}: B_{80}$ during the last 1 week. SR4SB2 represents $\mathrm{R}_{80}: \mathrm{B}_{20}$ during the first 4 weeks and $\mathrm{R}_{20}: \mathrm{B}_{80}$ during the last 2 weeks. SR3SB3 represents $R_{80}: B_{20}$ during the first 3 weeks and $R_{20}: B_{80}$ during the last 3 weeks. SB6 represents $R_{20}: B_{80}$ during the full 6 weeks.

significantly increased the $a^{*}$ value and decreased the $b^{\circ}$ value.

As shown in Table 5, the SR6 treatment had the highest EY and PY, which indicated that this treatment was most beneficial for increased FW. The SR5SBI treatment had the highest $\mathrm{EY}_{\mathrm{A}}$ and $\mathrm{PY}_{\mathrm{A}}$, indicating that it was the most beneficial for anthocyanin accumulation. Interestingly, following an increase in the number of weeks of $\mathrm{R}_{20}: \mathrm{B}_{80}$ usage, the OPE value also significantly increased, which indicated that this light quality treatment provided a greater number of photons per kilowatt hour of electricity than the $\mathrm{R}_{80}: \mathrm{B}_{20}$ treatment.

The relative $\mathrm{EY}(\mathrm{rEY})$, relative $P Y(r P Y)$, relative $\mathrm{EY}_{\mathrm{A}}\left(\mathrm{rEY}_{\mathrm{A}}\right)$, and relative $\mathrm{PY}_{\mathrm{A}}\left(\mathrm{rPY}_{\mathrm{A}}\right)$ represent the ratios of an electric light source to that of the control group (CW). SR6 treatment had the highest rEY and rPY. Considering the electricity consumption of photon generation, this indicated that using the SR6 light source resulted in $18 \%(\mathrm{EY})$ and $65 \%$ (PY) more FW, respectively, compared with using the CW light source. SR5SBl treatment had the highest
$\mathrm{rEY}_{\mathrm{A}}$ and $\mathrm{rPY}_{\mathrm{A}}$, which indicated that when consuming the same kilowatt hours of electricity or producing the same number of photons, this treatment resulted in $159 \%(\mathrm{EY})$ and $256 \%$ (PY) more anthocyanin yield, respectively, compared with CW treatment.

\section{Discussion}

Chlorophyll a and $\mathrm{b}$ have absorption peaks for blue light (430-453 $\mathrm{nm})$ and red light $(642-663 \mathrm{~nm})$ (Hopkins and Hüner, 2004). Previous studies have found that red light promoted the growth of lettuce (Johkan et al., 2010; Lee et al., 2010). Plant pigments can use red light to increase the carbon dioxide concentration in mesophyll cells, thus increasing the photosynthetic rate (Folta and Childers, 2008; Olsen et al., 2002). Research comparing the use of red-blue LEDs $\left(\mathrm{R}_{70}: \mathrm{B}_{30}\right)$ compared with white LEDs for the cultivation of lettuce found that redblue LEDs can significantly increase the shoot dry weight, chlorophyll $\mathrm{a}$ and $\mathrm{b}$ content, and net photosynthetic rate (Amoozga et al., 2017). An analysis of a lettuce growth model found that among various types of green light, yellow-green light $(575-625 \mathrm{~nm})$ resulted in the lowest growth efficiency (Dougher and Bugbee, 2001; Kong et al., 2015). The amount of green light in the $\mathrm{CW}$ treatment of this study reached $50 \%$; therefore, it may have been one of the causes of inhibited red leaf lettuce growth.

Light quality ratios with high red light and low blue light can significantly increase the content of chlorophyll $\mathrm{a}$ and $\mathrm{b}$ and carotene, and the increase in carotene content provides a mechanism for the photoprotection of a plant to reduce the damage caused by free radicals (Johkan et al., 2010; Schagerl and Müller, 2006). This study also found that treatments with more than $50 \%$ blue light significantly suppressed plant growth, which is consistent with the findings of previous studies (Son and $\mathrm{Oh}$, 2013).

Total phenol content is a general term for various secondary metabolites of plants, among which anthocyanin is a water-soluble antioxidant that mostly exists in vacuoles. They are primarily found in the petals, leaves, and seeds of plants as blue and purple pigments (Takeoka et al., 1997), and they protect plants and reduce the effects of light stress (Tattini et al., 2004). Son and Oh (2013) used red and blue LEDs to cultivate red leaf lettuce and found that FW and total phenol content were negatively correlated $\left(r^{2}=0.7219\right)$. However, treatment with more blue than red light $\left(\mathrm{R}_{41}: \mathrm{B}_{59}\right)$ significantly increased the total phenol content compared with $R_{87}: B_{13}$ treatment, but it decreased the FW of lettuce. This result was consistent with the findings of the present study.

Phenylalanine ammonia-lyase (PAL) and chalcone synthase (CHS) are key enzymes in the biosynthetic pathway of anthocyanin, and high blue light quality treatments (at least $\mathbf{5 0 \%}$ of total PPFD) can increase PAL activity (Heo et al., 2012). Moreover, when red leaf lettuce was cultivated for 1 week, first with red light and then with blue light, substantial accumulations of PAL and CHS were found (Son et al., 2017). This indicated that blue light can stimulate the biosynthesis of these two enzymes to increase the AC; however, the FW of lettuce tended to be decreased. 


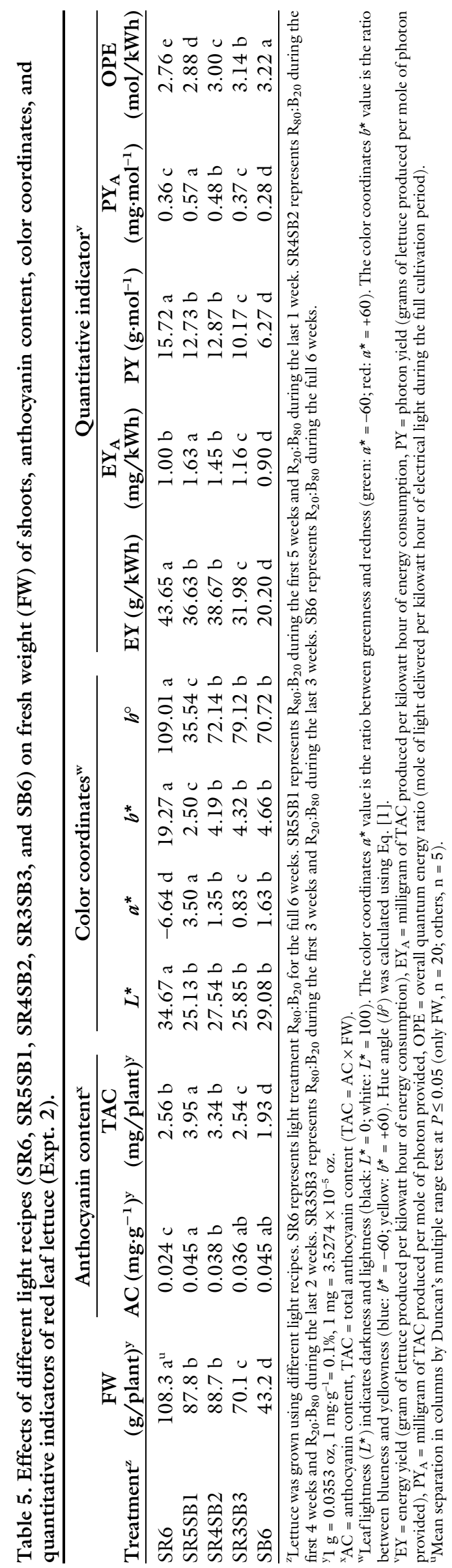

This study also found that increasing the proportion of blue light significantly increased the AC in red leaf lettuce (Table 4); however, incomplete color changes were found in leaves underneath areas of leaf overlap, possibly because the blue light was absorbed by the leaves above them; therefore, the lower leaves were not illuminated sufficiently by blue light.

Red leaf lettuce must turn red to have acceptable market value (Owen and Lopez, 2015). A color scale $\left(b^{\circ}\right)$ indicates redness $\left(0^{\circ}\right)$, yellowness $\left(90^{\circ}\right)$, greenness $\left(180^{\circ}\right)$, or blueness $\left(270^{\circ}\right)$ of the lettuce. Owen and Lopez (2015) cultivated red leaf lettuce in greenhouses and found that using red and blue LEDs $\left(\mathrm{R}_{50}: \mathrm{B}_{50}\right)$ for 1 week before harvesting significantly decreased the hue angle value $\left(b^{\circ}=30.7-40.6\right)$, indicating successful color change from green $\left(b^{\circ}=\right.$ 107.3-1 14.8) to red. In their control group (supplemental white LED lamps in a greenhouse), the leaves tended to turn green. This result was similar to that of the present study (SR5SBI and SR6 hue angle values were 35.54 and 109.01 , respectively) (Table 5). The present study used treatments with light changes during the cultivation process to reach a balance between yield and quality. An effective technique is promoting the accumulation of primary metabolites during an early stage of cultivation to cause plant growth, followed by short-term use of high levels of blue light to stimulate the plant to biosynthesize anthocyanin during the final stage of cultivation. Prolonging the period of high levels of blue light during quality treatment did not have a significant positive effect on the accumulation of TAC, possibly because the FW decreased due to the prolonged period of treatment with the high blue light (Table 5). During the last week of cultivation, the SRSBl treatment group received $\mathrm{R}_{20}: \mathrm{B}_{80}$ treatment. These results were compared with the results of $\mathrm{R}_{80}: \mathrm{B}_{20}$ use during the entire growing period. Although SR5SBI treatment decreased FW by $\approx 19 \%$, AC was increased by $\approx 90 \%$ and TAC of the entire plant was, in comparison with the plants in the $\mathrm{R}_{80}: \mathrm{B}_{20}$ treatment group during the entire growing period, increased by $54 \%$ (Table 5 ). 
Kozai (2013) proposed an indicator to calculate the efficiency of the use of electric lighting in plant factories and the efficiency of the use of light energy by plants $\left[\mathrm{LUE}_{\mathrm{P}}\right.$ (in grams dry weight per mole)], which was defined as the ratio of the accumulated dry weight and the light received by the plant. The EY and PY used in the present study were different from the concept of $\mathrm{LUE}_{\mathrm{P}}$. Equations for EY and PY both use the FW of a plant in the numerator, and EY uses the electrical energy consumed by lighting in the denominator, whereas PY uses the number of photons provided to the cultivation area as the denominator, which includes the entire growing cycle from sowing to harvesting. Commercially sold vegetables are valued according to FW, and the costs of light sources are typically calculated using the electricity consumed by the lighting system. Therefore, EY and PY may have more practical value than $L_{U E}$. The LUE values for tomato (Solanum lycopersicum) seedlings are $\approx 0.017$ in greenhouses and $\approx 0.038-0.042$ in plant factories. Plant factories have been reported to have 2 - to 2.5 -times more light use efficiency than greenhouses (Shibuya and Kozai, 2001; Yokoi et al., 2003). As shown in Table 5, EY was $20-45 \mathrm{~g} / \mathrm{kWh}$ and PY was $\approx 6-16 \mathrm{~g} \cdot \mathrm{mol}^{-1}$. When using these parameters to compare different cultivation methods, their respective definitions should be considered.

Previous studies have primarily focused on seedlings; however, the present study calculated the EY and PY of red leaf lettuce cultivated using different electric light sources in plant factories during the entire growing period (Shibuya and Kozai, 2001; Yokoi et al., 2003). The photosynthesis of red leaf lettuce is usually lower than that of green leaf lettuce (Lee et al., 2017). Additionally, the EY of red leaf lettuce is also lower than that of green leaf lettuce [the research team of the present study used CW to cultivate Boston lettuce with an EY of $\approx 80-100 \mathrm{~g} / \mathrm{kWh}$ (unpublished data)]. The increased EY and PY values were due to the enhanced effectiveness of the light supply. Moreover, the increased efficiency of the lighting itself or improvements in cultivation methods can be used to achieve increased crop FW. Changing from fluorescent lamps to LEDs can result in an increase in lighting efficiency of $\approx 60 \%$ (Kozai, 2013). Among the LED systems used, the different spectra also resulted in changes of $54 \%$ (EY ration, $\mathrm{SB} 6 / \mathrm{CW}$ ) to $118 \%$ (EY ration, $\mathrm{SR} 4 \mathrm{SB} 2 / \mathrm{CW})$ and of $100 \%\left(\mathrm{EY}_{\mathrm{A}}\right.$ ration, $\mathrm{CW} / \mathrm{CW})$ to $259 \%\left(\mathrm{EY}_{\mathrm{A}}\right.$ ration, SR5SBl/CW) for $\mathrm{rEY}$ and $\mathrm{rEY}_{\mathrm{A}}$ performance, respectively. Different electric light sources and cultivation processes also affect the energy consumed by each plant. In terms of the OPE (moles per kilowatt hour), CW was the most efficient electric light source (Table 4). However, for cultivation of red leaf lettuce, considering TAC and color change, CW was not the most efficient (Table 4). Our experiments used EY and PY to represent the red leaf lettuce FW and TAC that could be produced per kilowatt hour of electricity consumed or per mole of photons (400-700 nm) delivered, respectively. These two values could be used to determine better strategies for the production of red leaf lettuce.

During Expt. 1, $\mathrm{R}_{80}: \mathrm{B}_{20}$ treatment was used to cultivate red leaf lettuce, resulting in significantly increased values of $\mathrm{EY}, \mathrm{EY}_{\mathrm{A}}, \mathrm{PY}$, and $\mathrm{PY}_{\mathrm{A}}$ (Table 4). Figure 2 shows that the color change in lettuce was incomplete: the high $b^{\circ}$ values in Table 4 indicate that the red leaf lettuce had leaves close to green, which is not desirable by the market. Furthermore, $\mathrm{R}_{80}: \mathrm{B}_{20}$ treatment significantly decreased AC (Table 4 ). The $\mathrm{R}_{80}$ $: \mathrm{B}_{20}$ spectrum increased the $\mathrm{EY}_{\mathrm{A}}$ and $\mathrm{PY}_{\mathrm{A}}$ values of red leaf lettuce because the overall increase in FW caused the total TAC of the entire plant to increase. $R_{20}$ : $\mathrm{B}_{80}$ treatment significantly increased AC and significantly decreased the $b^{\circ}$ value, which indicated that this treatment was beneficial for leaf color change.

The results of Expt. I showed that $\mathrm{R}_{80}: \mathrm{B}_{20}$ treatment was beneficial for yield increase, whereas $\mathrm{R}_{20}: \mathrm{B}_{80}$ treatment was beneficial for color change and increased anthocyanin content. Expt. 2 attempted to combine the advantages of both treatments. $\mathrm{R}_{80}: \mathrm{B}_{20}$ treatment was first used to produce primary metabolites in red leaf lettuce (i.e., biomass), and $\mathrm{R}_{20}: \mathrm{B}_{80}$ treatment was used during the end of production to stimulate and induce anthocyanin production. SR5SB I treatment significantly increased the $\mathrm{PY}_{\mathrm{A}}$ of red leaf lettuce, and the change to $\mathrm{R}_{20}: \mathrm{B}_{80}$ treatment during the last week of the cultivation period, in comparison with SR6 treatment (i.e., $\mathrm{R}_{80}: \mathrm{B}_{20}$ light for the entire 6-week growing period), caused the efficiency of photon use in anthocyanin production in lettuce to increase by $58 \%$. During red leaf lettuce production, the FW of each plant and the secondary metabolite content must be considered. Using the control group $(\mathrm{CW})$ as a standard to evaluate the differences among the electric light sources, a comprehensive evaluation (FW accumulation and anthocyanin content) indicated that 1 week of blue light at the end of cultivation (light recipe: SR5SBI) is recommended for commercial use.

\section{Conclusions}

Among the four types of light quality treatments used in this study, those with high amounts of blue light were able to effectively increase the anthocyanin content of the leaves; however, they inhibited growth. With regard to total anthocyanin content per plant, if using the same light quality treatment throughout the growing period is required and the primary consideration is yield, then $\mathrm{R}_{80}: \mathrm{B}_{20}$ treatment is recommended. To maximize the red color, $\mathrm{R}_{50}: \mathrm{B}_{50}$ treatment can be used for the entire growing period. However, a more suitable cultivation method is $\mathrm{R}_{80}: \mathrm{B}_{20}$ treatment during the first 5 weeks and then changing the treatment to $\mathrm{R}_{20}: \mathrm{B}_{80} \mathrm{l}$ week before harvest. This lighting strategy can balance both yield and anthocyanin content.

\section{Literature cited}

Amoozga, A., A. Mohammad, and M.R. Sabzalian. 2017. Impact of light-emitting diode irradiation on photosynthesis, phytochemical composition and mineral element content of lettuce cv. Grizzly. Photosynthetica 55:85-95.

Dougher, T.A.O. and B. Bugbee. 2001. Evidence for yellow light suppression of lettuce growth. Photochem. Photobiol. 73:208-212.

Fang, W. 2013. Quantification of performance in plant factory, p. 64-71. In: Q. Yang, T. Kozai, and G.P.A. Bot (eds.). Technology advances in protected horticulture-proceedings of 2013 the $3 \mathrm{rd}$ high-level international forum on protected horticulture (Shouguang, China). China Agr. Press, Beijing, China.

Fletcher, R.S., T. Slimmon, and L.S. Kott. 2010. Environmental factors affecting the accumulation of rosmarinic acid in spearmint (Mentha spicata L.) and peppermint 
(Mentha piperita L.). Open Agr. J. 4:1016.

Folta, K.M. and K.S. Childers. 2008. Light as a growth regulator: Controlling plant biology with narrow-bandwidth solid-state lighting systems. HortScience 43:1957-1964.

Gazula, A., M.D. Kleinhenz, J.C. Scheerens, and P.P. Ling. 2007. Anthocyanin levels in nine lettuce (Lactuca sativa) cultivars: Influence of planting date and relations among analytic, instrumented, and visual assessment of color. HortScience 42:232-238.

Heo, J.W., D.H. Kang, H.S. Bang, S.G. Hong, C.H. Chun, and K.K. Kang. 2012. Early growth, pigmentation, protein content, and phenylalanine ammonia-lyase activity of red curled lettuces grown under different lighting conditions. Korean J. Hort. Sci. Technol. 30:6-12.

Hopkins, W. and N. Hüner. 2004. Introduction to plant physiology. 4th ed. Wiley, New York, NY.

Hung, K.T., D.G. Cheng, Y.T. Hsu, and C.H. Kao. 2008. Abscisic acid-induced hydrogen peroxide is required for anthocyanin accumulation in leaves of rice seedlings. J. Plant Physiol. 165:1280-1287.

Johkan, M., K. Shoji, F. Goto, S.N. Hashida, and T. Yoshihara. 2010. Blue light-emitting diode light irradiation of seedlings improves seedling quality and growth after transplanting in red leaf lettuce. HortScience 45:1809-1814.

Kong, S.W., H.Y. Chung, M.Y. Chang, and W. Fang. 2015. The contribution of different spectral sections to increase fresh weight of boston lettuce. HortScience 50:1006-1010.

Kozai, T. 2013. Resource use efficiency of closed plant production system with artificial light: Concept, estimation and application to plant factory. Proc. Jpn. Acad., Ser. B, Phys. Biol. Sci. 89:447461.

Lee, J.G., S.S. Oh, S.H. Cha, Y.A. Jang, S.Y. Kim, Y.C. Um, and S.R. Cheong. 2010. Effects of red/blue light ratio and short-term light quality conversion on growth and anthocyanin contents of baby leaf lettuce. J. Bio-Environ. Control 19:351-359.

Lee, J.H., P. Felipe, Y.H. Yang, M.Y. Kim, O.Y. Kwon, D.E. Sok, H.C. Kim, and M.R. Kim. 2009. Effects of dietary supplementation with red-pigmented leafy lettuce (Lactuca sativa) on lipid profiles and antioxidant status in C57BL/6J mice fed a high-fat high-cholesterol diet. Brit. J. Nutr. 101:1246-1254.

Lee, J.W., W.H. Kang, K.S. Park, and J.E. Son. 2017. Spectral dependence of electrical energy-based photosynthetic efficiency at single leaf and canopy levels in green- and red-leaf lettuces. Hort. Environ. Biotechnol. 58:111-118.

Li, Q. and C. Kubota. 2009. Effects of supplemental light quality on growth and phytochemicals of baby leaf lettuce. Environ. Expt. Bot. 67:59-64.

Lu, N., E.L. Bernardo, C. Tippayadarapanich, M. Takagaki, N. Kagawa, and W. Yamori. 2017. Growth and accumulation of secondary metabolites in perilla as affected by photosynthetic photon flux density and electrical conductivity of the nutrient solution. Front. Plant Sci. 8:708.

Nishimura, T., K. Ohyama, E. Goto, and N. Inagaki. 2009. Concentrations of perillaldehyde, limonene, and anthocyanin of Perilla plants as affected by light quality under controlled environments. Scientia Hort. 122:134-137.

Olsen, R.L., R.B. Pratt, P. Gump, A. Kemper, and G. Tallman. 2002. Red light activates a chloroplast-dependent ion uptake mechanism for stomatal opening under reduced $\mathrm{CO}_{2}$ concentrations in Vicia spp. New Phytol. 153:497-508.

Owen, W.G. and R.G. Lopez. 2015. Endof-production supplemental lighting with red and blue light-emitting diodes (LEDs) influences red pigmentation of four lettuce varieties. HortScience 50: 676-684.

Sazvar, Z., M. Rahmani, and K. Govindan. 2018. A sustainable supply chain for organic, conventional agro-food products: The role of demand substitution, climate change and public health. J. Clean. Prod. 194:564-583.
Schagerl, M. and B. Müller. 2006. Acclimation of chlorophyll a and carotenoid levels to different irradiances in four freshwater cyanobacteria. J. Plant Physiol. 163:709-716.

Shibuya, T. and T. Kozai. 2001. Light-use and water-use efficiencies of tomato plug sheets in the greenhouse. Envrion. Control Biol. 39:35-41.

Son, K.H., J.H. Lee, Y. Oh, D. Kim, M.M. Oh, and B.C. In. 2017. Growth and bioactive compound synthesis in cultivated lettuce subject to light-quality changes. HortScience 52:584-591.

Son, K.H. and M.M. Oh. 2013. Leaf shape, growth, and antioxidant phenolic compounds of two lettuce cultivars grown under various combinations of blue and red light-emitting diodes. HortScience 48:988-995.

Takeoka, G.R., L.T. Dao, G.H. Full, R.Y. Wong, L.A. Harden, R.H. Edwards, and J.D.J. Berrios. 1997. Characterization of black bean (Phaseolus vulgaris L.) anthocyanins. J. Agr. Food Chem. 45:33953400 .

Tattini, M., C. Galardi, P. Pinelli, R. Massai, D. Remorini, and G. Agati. 2004. Differential accumulation of flavonoids and hydroxycinnamates in leaves of $\mathrm{Lig}$ ustrum Vulgare under excess light and drought stress. New Phytol. 163:547561 .

Tsormpatsidis, E., R.G.C. Henbest, N.H. Battey, and P. Hadley. 2010. The influence of ultraviolet radiation on growth, photosynthesis and phenolic levels of green and red lettuce: Potential for exploiting effects of ultraviolet radiation in a production system. Ann. Appl. Biol. 156:357-366.

Yamazaki, K. 1982. Nutrient solution culture. Pak-Kyo, Tokyo, Japan.

Yokoi, S., T. Kozai, K. Ohyama, T. Hasegawa, C. Chun, and C. Kubota. 2003. Effects of leaf area index of tomato seedling populations on energy utilization efficiencies in a closed transplant production system. Shokubutsu Kojo Gakkaishi 15:231-238. 